\title{
Mind Maps to Modify Lack of Attention among Saudi Kindergarten Children
}

\author{
Bulquees Ismail Abdul Majid Daghistan ${ }^{1}$ \\ ${ }^{1}$ College of Education, King Saud University, Saudi Arabia \\ Correspondence: Bulquees Ismail Abdul Majid Daghistan, College of Education, King Saud University, Prince \\ Turkey street, Exit2, Riyadh, Saudi Arabia. Tel: 9665-5520-1276. E-mail:daghistanib@gmail.com
}

Received: September 18, 2015

Accepted: October 20, 2015 Online Published: March 29, 2016

doi:10.5539/ies.v9n4p245

URL: http://dx.doi.org/10.5539/ies.v9n4p245

\begin{abstract}
This research study aims at investigating the impact of Mind Maps on modifying the lack of attention in Arabic language class among Saudi Kindergarten children. To achieve the goals of this study the researcher used an experimental design with a random sample from AlRae'd Kindergarten's children in Riyadh -Saudi Arabia for the academic year (2014-2015). The study sample consisted of (40) children divided into two groups: (23) in the experimental and (17) in the control group. The researcher used Al-Obeidi's (1999) Lack of Attention Scale LAS. Validity of the tool was approved through a half division to measure lack of attention (0.93) which is considered good. The scale was used before and after the implementation of the experiment on both groups. Results showed a positive change in attention concentration in favor of the experimental group. Thus, the researcher recommended the use of Mind Maps in teaching kindergarten children to avoid attention deficiency.
\end{abstract}

Keywords: impact, mind mapping, treating, attention, deficiency, Saudi, kindergarten, children

\section{Introduction}

\subsection{Introduction}

Mind Maps are considered as an effective tool in active learning strategies that enhance memory to retrieve information and generate new creative unfamiliar ideas (Bozan, 2007). They work in the same steps that employ the human mind in activating and using brain effectively to arrange information in a way that helps mind to read and remember information instead of the traditional thinking process (Willis \& Miertschin, 2006)

Mind Maps are also used as a strategy to teach the educational concepts through lines which are called linking words to clarify the relationship between the concept and others in the form of a hierarchical sequential structure. The more general and inclusive concepts are placed at the top of the map, and more specific concepts at the base of the map (Bozan, 2007). The relations between concepts are represented through different colored arrows. These arrows indicate the level of differentiation between the relationships of concepts. Some relations between concepts are clarified by words or phrases written on the linking lines.

Mind mapping is described as a modern teaching strategy which helps in accelerating learning and knowledge discovery (Willis \& Miertschin, 2006). This self-learning strategy characterized the learner by rapid ability in: arranging ideas, speed learning, and quick information retrieval. Mind Maps help in arranging the sequence of ideas, where the learners start from a specific focal point, and then allow the flow of ideas and give the mind absolute freedom to generate ideas. They can be used in various fields of life and improve learning and thinking (Mitchell \& Smith, 2009). Moreover, the clearest way and the best performance of a human is the result of using branches, images and colors in Mind Maps to express their ideas which rely on visual memory to illustrate easy review and remember the rules and instructions.

Mind Maps are classified into two types; the traditional Mind Maps, and the Electronic-based Mind Maps (Mitchell \& Smith, 2009):

1) Traditional Mind Maps: this type uses colorful pens and paper. It starts by drawing a circle which represents the idea or the main subject. Then, a number of colorful branches are distributed around the main idea. It is permitted to write only one word or put a symbolic image on each branch to represent a minor idea. However; each branch of the main branches can shift to other secondary minor branches represent other sub-minor ideas of this section. In the end, there will be a form like a tree or map hich reflects the main idea in all its aspects. 
2) Electronic -based Mind Maps: this type uses computer programs in designing Mind Maps such as; IMindMap, MindView3, FreeMind9, MindManager8.These programs do not require special graphical skills from the users since they are automatically synthesized maps with curved smooth branches. They also allow Drag and shed Pictures which add powerful new possibilities and capabilities of Mind Maps which help in generating new ideas and see links between existing ideas in a short time. They also allow updating the contents of the map as needed, making it a powerful tool for tracking and progress continuously and can therefore develop the current map so that it becomes another new innovative and creative map, and this is not offered by the traditional Mind Maps.

\subsection{Advantages of Mind Maps in Education}

There are many advantages of the use of Mind Maps in education, including the following (Bozan, 2007):

1) Make learning more fun.

2) Give a comprehensive picture about the subject that is being studied so that a more holistic subject is displayed.

3) Help to generate ideas and design complex structure of knowledge.

4) Operate to deliver complex ideas and help the learner to connect the new knowledge with previous knowledge.

5) Put as much information as possible on one sheet of paper.

6) Managed to put everything that goes on in the mind of the learner and all ideas thread on one sheet of paper.

7) Make educated decisions more correct. When placed in a single sheet, it can be seen as a comprehensive view of all aspects.

8) Operate on the development of the learner's memory and increase its focus.

9) Help the learner to use the entire brain power.

10) Facilitate the study of difficult subjects.

11) Provide a framework for the visual presentation of knowledge.

12) Increase the ability to remember and focus during learning, where learners controls the feeling of self-confidence and in the mental capacity.

According to child education, it is emphasized that the children have the ability to represent knowledge in a visual chart using colors and pictures developmentally (Smith, Cowie, \& Blades, 2001). The studies that have explored the practical usage of Mind Maps in preschool education suggest that Mind Maps are efficient in aiding children to see and express the relationships among ideas (Badilla, 2014; Figueiredo, Lopes, Firmino, \& de Sousa, 2004; Mancinelli, Gentili, Priori, \& Valitutti, 2014). In sum, Mind Mapping is a useful instructional tool even in preschool education. It helps children to see concepts and the relationships between them and externalize their ideas. They also help teachers to assess children's conceptual development and understanding, and build new knowledge above old knowledge. In preschool education, once familiar with the idea and the process of Mind Mapping, children can erect their own maps either individually or collaboratively.

To sum up, Mind Mapping is an active learning strategy. It increases the ability to arrange the big ideas and the speed of learning and information retrieval.It also increases the love of learning among learners. It is a chance to involve learners in the procedure of their learning. Mind Maps are described as a method of visual thinking on paper. a process that can show students "unexpected connections or identify holes or contradictions in their 'theory' and help them to figure out ways to resolve them". Finally; Mind Maps can be constructed either by hand or using specific software programs. The main benefit of using a computer is that ideas and links can be easily controlled and updated while the format can be modified or enhanced visually by inserting colorful symbols, pictures, connectors, or clip arts (Dormer, 2009).

\section{Literature Review}

\subsection{Theoretical Background}

\subsubsection{What is a Mind Map?}

A Mind Map is an application of Ozbel theory which assumed that learner's brain stores information in the form of sequential hierarch from general to specific to facilitate its learning and retrieval (Attiyah, 2008). Therefore they should be presented in a suitable manner in the form of generalized summary that includes thought anchors fixing new information in the learner's mental structure (Mari' \& Al-Hilah, 2012). This was also emphasized by 
Buzan (2007) when pointing out that every individual has knowledge structure of certain type. When he experiences new learning experience, the new information joins that knowledge structure and brings reformed after experiencing a new experience. Then, the new information integrates to become an integral part of the total knowledge structure which can be presented in one chart which is called a Mind Map.

Given that meaning, full learning is achieved basically through linking new learning with existing thought in knowledge structure. Teachers ought to link what a learner knows with what he learns. Full learning could not occur unless the material structure is organized clearly and related to the new material. Consequently, that helps in deepening learner's ability in retaining and retrieving new material (Abu-Jado, 2009). That is what Mind Maps function as a tool for organizing ideas and meanings included in the subject or study unit. Mind Maps help students organizing their knowledge in order to deepen their learning of study unit or syllabus (Attiyah, 2008). Buzan (2007) pointed out several essential situations of using Mind Maps in education:

- When the teacher wants to assess learners' previous knowledge on the new learning subject.

- When the teacher wants to evaluate the level of students' level in new concepts recognition.

- When the teacher wants to plan learning to be based on a structure of concepts included in the topic and how to be presented.

- When formulating lesson's summary.

- When the teacher wants to relate old with new information.

- When planning curriculum.

- When organizing learners' knowledge structures and making them mastering the material.

- When the teacher wants to deepen learners' understanding and learning.

- When the teacher wants to reinforce the educational achievement.

\subsubsection{Components of Mind Maps}

Mind Maps include the following components:

- Main idea or concept: it is a mental structure results from common features of a phenomena or mental representation of objects made by the person.

- Connective words: words used to connect two or more concepts.

- Horizontal links: a link between two or more concepts of the hierarchical sequence and represented in a horizontal line.

- Examples: determined events or actions that express concept example (Al-Khataibeh, 2008).

\subsubsection{Lack of Attention}

Lack of attention is one of the most common and widespread behaviors among children. Such a phenomenon became the focus of courtesy for researchers, educators and parents. It has negative effects on children's learning and cognitive level (Al Asimy, 2008). It received a great interest among psychologists because it addressed unusual behavior through learning (Ali, 2009). It causes a learning difficulty since children display movements that are above the required and tend to be impulsive in performing what is required from them. It is known that pupils' attention to teachers means freeing themselves of all external stimuli whether those resulting from their classmates or whatever noise or distractor, through the class to be able to follow their teacher's instructions and information (Botros, 2009). It is not easy to motivate them to perform school tasks (Assaid, 2003).

Lyon (2002) believed that children with lack of attention, suffer from learning problems which become clear on them through their study stages. They are unable to concentrate for long periods of time or might suffer from hyperactivity. They face a difficulty in focusing their attention and maintain it for a relative period when performing different activities as writing school's works and listening to the teacher while explaining a lesson (Al-Asimy, 2008).

Therefore (Botros, 2009) indicated that lack of attention has symptoms that appear on pupils through different situations, which indicate maladaptation, whether they are normal with lack of attention or special education pupils, including:

- Difficulty in offending details and committing many naïve mistakes in their school assignments or works or other activities.

- Difficulty in focusing attention, on tasks they perform or play activities in which they participate, for a long 
period of time

- Look like as they are not hearing teachers when talking to them directly, and suffer from a difficulty in listening.

- Do not follow directions in completing jobs which are required from them either at home or at school.

- $\quad$ Find difficulty in arranging (Ordering) tasks and activities, as well as in their organization.

- $\quad$ Avoid participation in requiring mental efforts.

- $\quad$ Loose necessary things for performing tasks such as school tools and instruments.

- $\quad$ Easily distracted attention by interfering stimuli.

- $\quad$ Forget much of the content.

For all the above, fretting lack of attention or attention deficit, through improving attention behavior to different situation in a given lesson, through a series of directions given by a teacher to a class group, becomes necessary (Al-Far, 2003).

Ali (2009) pointed some treatment techniques for lack of attention through the following:

1) Training on attention concentration: through drawing pupils' attention towards important stimuli to concentrate on, simplifying introduced stimuli and decreasing their numbers, eliminating their complexities for the student to attend to and comprehend, as well as using new stimuli and experiences, besides using pupil's previous experiences as a starting point in providing new educational experiences.

2) Increasing attention period: through determining what should be done and accomplished. The teacher is advised to use a stop watch, providing rest periods between training on increasing attention tasks and giving pupils a reinforce and reward to encourage the increase in attention.

3) Increasing flexibility in attention transfer, by providing enough time for the student to move from one stimuli to another with gradual decrease in attention transfer period.

4) Improving attention process sequence: It means that the learner concentrates his mind and senses in successive stimuli through educational experiences' presentation. On the other hand, the teacher increases the number of teaching paragraphs and tasks gradually until the learner makes a control on the educational task.

\subsection{Significant Previous Studies}

This portion of the current study is dedicated to present some significant previous studies that are related to the issue of this research. Osten's (2013) study aimed at finding out the effect of using Mind Maps on improving $1^{\text {st }}$ grade female students English words' retention in English as a foreign language class. The study was conducted on a sample of (60) first grade female students in one of the public schools in Sweden. The sample was divided equally on two groups; an experimental group taught by Mind Maps and a control group taught via the traditional method. Results showed a statistically significant difference between mean scores of the experimental group's students and that of control group's students in pre-post tests of vocabulary.

Raji (2013) conducted a study aiming at finding out the effect of using Mind Maps and learning cycle in providing and maintaining science concepts in science education for fifth grade female students. The study was conducted on a sample of (58) female students assigned evenly between experimental group taught by Mind Maps and another experimental group taught by Learning cycle group over equivalent in some variables, 16 Mind Maps were prepared within (16) major concepts as well as a test on providing science concepts' recognition, classification, and generalization. Results showed that the experimental group taught by Mind Maps outperformed the other group in acquiring and retaining concepts.

Al-Yousfani's (2005) study aimed at finding out the effect of using Mind Maps on providing fifth grade female students with some geographical concepts. The study was conducted on a sample of (56) fifth grade female students divided equally on two groups; experimental taught by Mind Maps and control one taught via the traditional method. Results showed a statistically significant difference between mean scores of experimental group's students and that of control group students.

Mohammed (2009) conducted a study aims at finding out the effect of using Mind Maps on first middle class female students in developing their rhetoric thinking. The study was conducted on (65) female students assigned to experimental group taught by Mind Maps, and control group taught by the traditional method. Results showed that experimental group performance on rhetorical thinking was superior to that of control group. 
Spinelli (2009) carried out a study aiming at finding out the effect of using Mind Maps in reducing the severity of attention deficiency symptoms accompanied with hyper activity through a set of cooperative activities among a sample of students with lack of attention totals (11) students between (7-9) years old in America. Results showed the effectiveness of Mind Maps in reducing the severity of lack of attention symptom accompanied with hyperactivity (cited in Ali, 2009, pp. 145-146).

Al-Mafraji's (2011) study aimed at finding out the effect of using both pictured story and Mind Maps in modifying lack of attention among kindergarten students. The study was conducted on a sample of (28) students distributed as follows: (9) students in the first experimental group taught by pictured story, (10) in the second experimental group taught by Mind Maps technique and (9) in the control group taught by the traditional method. Groups were equivalent on some variables (chronical age by months, general average, father's level of education, mother's level of education, pretest of lack of attention score). Results showed the superiority of both first and second experimental groups compared to control in modifying lack of attention.

\subsubsection{Indications and Suggestions from Previous Studies}

\subsubsection{Objectives}

Osten (2013) targeted to find out the effect of Mind Maps on improving English vocabulary retention of the first grade students in Sweden. On the other hand, Raji (2013) aimed at finding out the effect of using Mind Maps and learning cycle in providing and retaining scientific concepts in science education. However; Al-Yosfani (2005) aimed at finding out the effect of using Mind Maps on providing fifth female graders some geographical skills. On the other study Mohammed (2009) aimed at finding out the effect of using Mind Maps on the first middle intermediates female students' acquisition in science and developing their rhetorical thinking. Spinelli's (2009) study aimed at finding out the effect of using Mind Maps in reducing severity of attention deficiency accompanied with hyperactivity through a set of cooperative activities among a sample of students with attention deficit.Finally Al-Mafraji (2011) aimed at finding out the effect of both pictured story and Mind Maps techniques in modifying lack of attention among kindergarten students.

\subsubsection{Sample}

It is noticed there was a difference in sample size according to experimental design, objectives and variables in each study, ranging from 11-65.

\subsubsection{Instruments}

Ospen (2013) designed a vocabulary test. On the other hand, Raji (2013) designed a test on providing scientific concepts, whereas Al-Yousfani (2005) prepared an instrument to measure geographical skills. However, Mohammed (2009) prepared two instruments; an acheivement test and rehotric thinking test. Spinelli (2009) used a lack of attention scale and diagnosis scale. Finally; Al-Mafraji (2011) used lack of attention scale.

\section{Method}

\subsection{Design}

The current study used the experimental design with two equivalent groups (experimental vs control) from AlRa'ed kindergarten in Riyadh -Saudi Arabia during the Academic year 2014-2015. The experimental group was taught the Arabic grammar by Mind Maps and the control group was taught by the traditional way during four months of the experiment.

\subsection{Population and Sample}

The pouplation is all the phenomena subjects studied by the researcher (Milhim, 2002).Population of this study included all kindergarten female children for the school year (2014-2015) in Riyadh city in Saudi Arabia.As for the study sample it was (40) children (23) in the experimental group and (17) children in the control group at Al-Rae'd Kindergarten school.

\subsection{Equivalence of the Groups}

Before conducting the research, the researcher was careful in making equivalence betwenn the two research groups in a number of variables that might affect the dependent variable as follows:
1) Chronical age by month.
2) Father's education.
3) Mother's education.
4) Lack of attention scores at pretest for both groups. Table 1 shows the results. 
Table 1. T value of equivalent variables for experimental and control groups

\begin{tabular}{lcccccc}
\hline Variables & Group & $\mathrm{N}$ & Mean & SD & Calculated T Vale & Tabulated T value \\
\hline Chronical age / Months & E & 23 & 121.875 & 7.33755 & \multirow{2}{*}{1.9820} & \\
& $\mathrm{C}$ & 17 & 127.6 & 4.9035 & & \\
Reading material degree & $\mathrm{E}$ & 23 & 7.875 & 1.7268 & & \\
& $\mathrm{C}$ & 17 & 7.7 & 1.6227 & 0.2210 & \\
Father's education & $\mathrm{E}$ & 23 & 8.3250 & 4.4057 & & \multirow{2}{*}{1.2844} \\
Mother's education & $\mathrm{C}$ & 17 & 6.2 & 3.6147 & & \\
& $\mathrm{E}$ & 23 & 7.125 & 1.5526 & & \\
Pre lack of attention scale & $\mathrm{C}$ & 17 & 6.4 & 3.8643 & & \\
& $\mathrm{E}$ & 23 & 62.75 & 15.7003 & \multirow{2}{*}{0.26333} & \\
\hline
\end{tabular}

Results in the above table showed no statistically significant differences between experimental and control groups at $(\alpha=0.05)$, where calculated T value was less than tabulated on which is (2.23) indicating that the two groups were equivalent on these variables.

\subsection{Educational Plans' Preparation}

The topics of Kindrgarten's Arabic language text book were determined by the Ministry of Education in Saudi Arabia for the year (2014-2015).They include Al- Ashshamsieh and Al-Qammarieh letters, Speech division, Masculine and Femminine Nouns, Single, Dual and Plural,and Relatives). Mean while, the researcher determined behavioral objectives in light of these topics utilizing Bloom's taxonomy in the cognitive domain within the three levels (knowledge, understanding, and application). In light of this, (12) educational plans were prepared for both groups. They were designed in light of using Mind Maps in teaching the previous topics of the Arabic language. Plans were given to a panell of referees specialized in psychological, educational sciences and teaching methods. Plans were modified according to their suggestions.

\subsection{Purpose of Study}

This study aimed at finding out the effect of Mind Maps on modifying lack of attention among Saudi kindergarten's children in the Arabic language class.

\subsection{Research Hypotheses}

The current study tried to approve or refuse the following hypotheses:

H1: There were statisically significant differences between pre and post tests of LAS for the experimental and control groups.

H01: There were no statisically significant differences between pre and post tests of LAS for the experimental and control groups.

H2: There were statistically significant differences between LAS means scores for pre and post test among control group's children.

H02: There were no statistically significant differences between LAS means scores for pre and post test among control group's children.

\subsection{Limitations of the Study}

The results of this study could not be generalized according to the following limitations:

1) The study was conducted on a sample of Kindergarten children in Riyadh city for the school year 2014/ 2015.

2) The study took place during the first semester of the academic year 2014/2015.

3) The study employed Kindergarten's Arabic language textbook for the year 2014-2015 (Al-Ashamsih and Al-Qamarih, Speech divisions, Masculine and Feminine Nouns, Single Dual and Plural, and Relatives). 


\subsection{Problem Statement}

Lack of attention and slow learning are two recent problems that appeared in education researches nowadays. The researcher of the current study noticed that some of the Saudi children suffer from slow learning because of lack of attention. This lack of attention depends on many reasons like hyperactivity, boring classroom environment, traditional teaching methods, lack of teaching aids, and poor teacher's experience (personal observation as a supervisor of kindergartens in Riyadh). The researcher also noticed that many difficulties facing Saudi kindergarten children in Arabic language material in addition to the common known problem among all pupils that is focusing attention during the teaching-learning process. In an attempt to assist children overcoming problems facing them in Arabic subject using an educational method that showed them concepts, meanings, and examples in the form of organized colorful charts surrounded with frames and arrows indicating the illustration of the material content. Using Mind Maps as an attractive and exciting method may work on the continuity of their attention to the presented material as well as constructing knowledge structure that is almost integrated in their minds to raise their attention in the classroom. Consequently, the problem of this research lies in the following research question: Would Mind Maps aid kindergarten children to modify their attention in classroom in a positive way?

\subsection{Procedural Terms of the Study}

\subsubsection{Mind Maps}

Mind Maps were defined by Buzan (2007) as a visual teaching methodology in the form of graphical charts. The main concept is connected to other concepts in the form of hierarchy to highlight relationships between concepts and ideas through curved colorful lines and connectives.

Al-Khataibeh (2005) defined Mind Maps as two dimensional graphs in which study material concepts are arranged in a hierarchy where concepts are arranged from general to specific ones and are surrounded with interrelated frames by arrows on which the type of relation is written. Attiyah (2008) defined Mind Maps as two dimensional pictures of the relationships between concepts or ideas expressed by sequential hierarchical organizations of concepts, names included in the subject.

Procedurally, Mind Maps are graphical pictures or charts prepared by the researcher for grammar concepts at kindergarten classroom. Children will be able to order these rules and concepts and display relationships among them so as they can perceive and understand them in an organized manner through arranged and attractive graphical charts which stimulate attention.

\subsubsection{Attention Deficiency}

Al-Obeidi (1999) defined attention deficiency as a behavioral inability to concentrate. Hyperactivity, impulses and difficulty to satisfy are their major components. Al-Asimi (2008) defined attention deficiency as a short attention period, mental distraction, passivity, anxiety and affective imbalance on both conscious and subconscious which leads to poor study achievement. Finally, Ali (2009) defined attention deficiency as a cognitive behavior disorder which leads to inability to concentrate or stimuli selection and these symptoms become intensive in situations requiring self-judgment.

Procedurally, lack of attention is defined as the scores earned by kindergarten children on Lack of Attention Scale LAS. The scores indicate the presence of lack and weak ability on concentrating and attending to stimuli as well as distinguishing between important and less important ones.

\subsubsection{Lack of Attention Scale(LAS)}

Lack of Attention Scale LAS prepared by Al-Obeidi (1999) for Kindergarten children consisting of (40) items with likert five point scale (Always, Mostly, Sometimes, Rarely and Never), See Appendix 1. After being submitted to a panel of referees, needed modifications were carried out.The modified responses became (Mostly, Sometimes and Rarely). Moreover,the scale was decreased to (38) items in its final version. Validity was established as a prerequisite condition of effective measurement. This means that the test is valid for users, examiners and examinees (Omar, 2010).

\subsection{The Experiment}

Before starting the experiment, a pretest was administred on both research groups. Also, the scale remained with two teachers of kindergartens that participated in the experiment for (3) days to take time in answering the scale carefully.

The real research experiment started on 20/1/2015, after completing research requirements: Equivalence of the groups, preparing educational plans and LAS.However, the experiment was terminated on 28/5/2015. 
A post test was conducted at the end of the experiment.Two teachers from AlRae'd Kindergarten were given LAS at the same day to have time answering it. The scale was recollected from the teachers after four days.

\subsection{Statistical Methods for Analysis of Pretest-Posttest Data}

The following statistical methods are traditionally used in comparing groups with pretest and posttest data: (1) Analysis of variance (ANOVA) on the gain scores, (2) Analysis of covariance (ANCOVA). In both of these methods, the use of pretest scores helps to reduce error variance, thus producing more powerful tests than designs with no pretest data. Generally speaking, the power of the test represents the probability of detecting differences between the groups being compared when such differences exist.

\section{Results and Discussion}

After scoring LAS, data was statistically analyzed to check research hypotheses, as follows.

H1: There were statisically significant differences between pre and post tests of LAS for the experimental and control groups.

H0: There were no statisically significant differences between pre and post tests of LAS for the experimental and control groups.

The difference mean scores of pre-post tests of LAS was (3.6250) for the experimental group, with SD (6.32314), and T.value of (3.8580) which was greater than the tabulated value (2.365), at $(\alpha=0.05)$. Table 2 shows these results.

Table 2. T value of pre and post test of lack of attention scale LAS among the experimental group

\begin{tabular}{|c|c|c|c|c|c|c|c|}
\hline \multirow{2}{*}{ Group } & \multirow{2}{*}{$\mathrm{N}$} & \multicolumn{3}{|c|}{ Mean } & \multirow[t]{2}{*}{ SD } & \multicolumn{2}{|c|}{ T value } \\
\hline & & Difference & Post & Pre & & Calculated & Tabulated \\
\hline Experimental & 23 & 3.500 & 5.1250 & 8.6250 & 6.32314 & 3.8580 & 2.3365 \\
\hline
\end{tabular}

Table 2 shows that there is a statistically significant difference between pre and post test scores of LAS among the children of the experimental group. This leads to accepting H1 Hypothesis and rejecting the null hypothesis. This result could be atributed to the role of Mind Maps in modifying attention deficiency among the experimentals in organizing and ordering material in a summarized form with simple and attractive charts causing children to concentrate on the material in this different way, See Appendix 2.

H2: There were statistically significant differences between LAS means scores for pre and post test among control group's children.

H0: There were no statistically significant differences between LAS means scores for pre and post test among control group's children.

Results showed that the mean difference between the pre and post tests for control group children was (.3300), with $(\mathrm{SD}=2.26323)$, and calculated $\mathrm{T}$. value was (4.61) which is greater than the tabulated one $(2.20)$ at $(\alpha=$ $0.05)$ level, and $\mathrm{df}=(16)$ as shown in Table 3.

Table 3. T values of pre and post tests for lack of attention scale for control group pupils

\begin{tabular}{lccccccc}
\hline \multirow{2}{*}{ Group } & \multirow{2}{*}{$\mathrm{N}$} & \multicolumn{3}{c}{ Mean } & \multicolumn{2}{c}{ SD } & \multicolumn{2}{c}{ T value } \\
\cline { 3 - 7 } & & Difference & Post & Pre & & Calculated & Tabulated \\
\hline Control & 17 & .3300 & 6.10000 & 6.43000 & 2.26323 & 4.611 & 2.262 \\
\hline
\end{tabular}

This suggests a slight difference between pre and post test where pre test score was higher in 0.3300 points, and so the null hypothesis is rejected. This slight difference is due to the teaher's role and the method used in teaching pupils even though was traditional, but a small modification happened to lack of attention among controls during the experiment.

Finally, the results showed that mean difference between pre and posttest for experimental group was (3.500), and for control group was $(.033000)$ with $\mathrm{SD}=6.32314$ and 2.26323 respectively, with a calculated $\mathrm{T}$ value (2.487) which is greater than the tabulated one $(2.120)$ at $(\alpha=0.05)$ and $\mathrm{df}=39$, as shown in Table 4. 
Tabel 4. T value for lack of attention modification for both experimental and control groups

\begin{tabular}{lccccc}
\hline \multirow{2}{*}{ Group } & \multirow{2}{*}{$\mathrm{N}$} & \multirow{2}{*}{ Mean } & \multirow{2}{*}{ SD } & \multicolumn{2}{c}{ Tvalue } \\
\cline { 5 - 6 } & & & & Calculated & Tabulated \\
\hline Experimental & 23 & 3.500 & 6.32314 & \multirow{2}{*}{2.487} & 2.120 \\
Control & 17 & 0.330 & 2.26323 & & \\
\hline
\end{tabular}

Results indicated a difference between attention deficiency modification mean score for experimental group and that for control group, where experimental group mean score was higher. This result clarifys the existence of a modification in lack of attention among the experimental group with a degree greater than that among control group pupils despite having a little modification in lack of attention, but when comparing mean difference between them was (3.170) which is due to the uniqueness of Mind Maps in organizing pupils' ideas and constructing a healthy knowledge structure because it atracted the attention that leads to reduce lack of attention and distraction (Al-Mafraji, 2011).

To conclude, and in light of the above findings Mind Maps helped in modifying lack of attention among kindergarten children in Arabic language classes in Saudi Arabia.

\section{Recommendations}

Based on the research results. The researcher recommends using Mind Maps in teaching Arabic Language for kindergarten children,and trainning kindergartens' teachers on the methods of using Mind Maps for its contribution to modifying lack of attention of kindergartens' students.In addition,the researcher suggests conducting a future study on the effect of using Mind Maps in acheivement and information retention among kindergarten children,and another study in other subject area to investigate the effect of using Mind Maps in lack of attention modification among kindergarten children in other learning subjects.

\section{Acknowledgements}

This is a research project that was supported by a grant from the Research Center for the Humanities, Deanship of Scientific Research at King Saud University.

\section{Refferences}

Abu-Jado, S. (2009). Educational psychology. Amman:Al-Maseerah Publishers.

Al-Asimi, R. (2008). Lack of Attention accompanied with Hyper Activity among children. Journal of Damascus University, 24(1), 53-103.

Al-Far, M. (2003). A Guide to learning difficulties. Amman: Yafa house publishers.

Alí-Arroyo, E. (2009). The development of Mind Maps with children in kindergarten and first grade. In A. J. Cañas, J. D. Novak, \& F. M. Gonzalez (Eds.), Proceedings of the 1st International Conference on Concept Mapping. Pamplona, Spain: Universidad Pública de Navarra. Retrieved March 28, 2015, from http://cmc.ihmc.us/CMC2004Programa.html

Al-Khataibeh, A. (2008). Teaching Arabic for all. Riyadh: Al-Maseerah publishers.

Al-Mafraji, O. (2011). The effect of pictured story and role play in modifying lack of attention among special education pupils (Unpublished Master thesis). Yarmouk University.

Al-Obeidi, Sh. (1999). Constructing lack of attention scale in elementary schools children, unpublished scale in elementary schools children (Unpublished master thesis). Al-Imam University.

Al-Yosfani, D. (2005). The effect of using Mind Maps in giving fifth elementary grade female students some geographical skills (Unpublished master thesis). Al-Sharjah University.

Assaid, A. (2003). Learning difficulties its history, nature, diagnosis, and treatement. Cairo: Al-Fiker Al-Arabi.

Attiyah, M. (2008). Modren strategies in effective teaching. Baghdad: Safa'a publishers.

Ausubel, D., Novak, J., \& Hanesian, H. (1978). Educational psychology: A cognitive view. New York: Holt, Rinehart \& Winston.

Badilla, S. (2014). Teaching experience: Mind Maps in preschool. In Memorias V Congreso Nacional de Educadores, Programa Nacional de Informática Educativa MEP-FOD (Preescolar, I y II Ciclos), San José, Costa Rica. Retrieved March 28, 2015, from http://www.fod.ac.cr/Vcongreso/CronoPonencias.htm 
Botros, H. (2009). Teaching learning difficulties students (1st ed.). Al-maseerah publishers, Amman.

Bozan, A. (2007). Mind Maps. New york: Oxford Press.

Dormer, S. (2009). Mind mapping. Tuggeranong, Australian Capital Territory: ACT Centre for Teaching and Learning. Retrieved April 5, 2015, from http://activated.det.act.gov.au/learning/word/elt/7.0_MindMapping. pdf

Ellozy, A., \& Mustafa, H. (2007). Concept Mind Mapping: Initial Experience and Lessons Learned (Part1). New Chalk Talk Series, 7(7). Center for Learning and Teaching, The American University in Cairo.

Erickson, H. (2002). Concept-based curriculum and instruction: Teaching beyond the facts. Thousand Oaks, CA: Corwin Press.

Figueiredo, M., Lopes, A., Firmino, R., \& de Sousa, S. (2004). “Things we know about the cow”: Mind mapping in a preschool setting. In A. J. Cañas, J. D. Novak, \& F. M. Gonzalez (Eds.), Proceedings of the 1st International Conference on Concept Mapping. Pamplona. Spain: Universidad Pública de Navarra. Retrieved February 2, 2015, from http://www.cmc.ihmc.us/papers/cmc2004-038.pdf

Gallenstein, N. (2005). Using Mind Maps to establish meaningful relationships. University of Hong Kong, Department of Curriculum and Instruction. Retrieved January 12, 2015, from http://www.fed.cuhk.edu.hk/ ; johnson/misconceptions/ce/learn/concept_map.htm

Jonassen, D., Reeves, Th., Hong, N., Harvey, D., \& Peters, K. (1997). Concept mapping as cognitive learning and assessment tools. Journal of Interactive Learning Research, 8(3-4), 289-308.

Lyon, R. (1998). A primer on Mind Maps. USAFA Educator, 7(1). Retrieved March 31, 2015, from http://academic.wsc.edu/frc/innovations.htm

Mancinelli, C., Gentili, M., Priori, G., \& Valitutti, G. (2014). Mind Maps in kindergarten. In A. J. Cañas, J. D. Novak, \& F. M. Gonzalez (Eds.), Proceedings of the 1st International Conference on Concept Mapping. Pamplona. Spain: Universidad Pública de Navarra. Retrieved March 2, 2015, from http://www.cmc.ihmc.us/papers/cmc2015-195.pdf

Mari', T., \& Al-Hilah, M. (2012). General Teaching methods. Baghdad: Al Fiker publishers.

Maxwell, J. (1996). Qualitative research design: An interactive approach. Thousand Oaks, CA: Sage.

McAleese, R. (2008). The knowledge arena as an extension to the mind map: Reflection in action. Interactive Learning Environments, 6(3), 251-272. http://dx.doi.org/10.1076/ilee.6.3.251.3602

McAleese, R. (2009). Mind mapping - a critical review. Innovation in Education and Training International, 36(4), 351-360. http://dx.doi.org/10.1080/1355800990360411

Mitchell, E., \& Smith, S. (2009). Instructional Design \& Educational Technology Tips. Free Mind Mapping Software, Wake Forest University.

Mohammed, B. (2009). The effect of using Mind Maps in science and developing their rehotric thinking. Third annual meeting of basic education college, 4, 228-262.

Novak, D., \& Gowin, D. (1984). Learning how to learn. Cambridge: Cambridge University Press. http://dx.doi.org/10.1017/CBO9781139173469

Novak, J., \& Cañas, A. (2006). The theory underlying Mind Maps and how to construct them (Technical report IHMC CmapTools 2006-01). Pensacola: Florida Institute for Human and Machine Cognition (IHMC). Retrieved May 22, 2015, from http://cmap.ihmc.us/Publications/ResearchPapers/TheoryUnderlyingConceptMaps.pdf

Omar, M. (2010). Education and psychological measurement. Amman:Al-Masseerah.

Osten, A. (2013). Using interviews and Mind Maps to access mentor teachers' practical knowledge. Higher Education, 46(2), 195-214.

Raji, Z. (2013). The effect of using Mind Maps and learning cycle on acquiring scientific concepts and retaining them in science among fifth grade female students (Unpublished master thesis). Jordan University.

Smith, P. K., Cowie, H., \& Blades, M. (2001). Understanding children's development (3rd ed.). Oxford: Blackwell.

Spinelli, E. (2009). Mind mapping: How should it be introduced, and is there evidence for long term benefit? Higher Education, 35(3), 317-328. 
Willis, C., \& Miertschin, S. (2006). Mind Maps as Active Learning. Journal of Computing Sciences in Colleges, 21(4).

\section{Appendix 1}

\section{Lack of Attention Scale}

1. Characterized with inability to concentrate for long time.

2. Easy distracted by any external stimulus.

3. Can not set stable in his disk for long time.

4. Can not wait in situations requiring that.

5. Not compliant with regulation and orders very well.

6. Forgets things.

7. Moves always when he is supposed to stay still.

8. Moves with no specific goal.

9. Does not wait his turn in a line.

10. Unoroganized home works.

11. Does not listen well to the lesson.

12. Has difficulty in playing with peers.

13. Asks leaving the class continuously.

14. Speaks before he is asked to.

15. Answers questions before they are completed.

16. Does not accomplish his tasks without rewards.

17. Does not attend to what he looses.

18. Forgets completing school and home works.

19. Jumps on the disk during the lesson.

20. Commits disruptive behaviors in the classroom.

21. Speaks rushly without thinking.

22. Interrupts others while speaking.

23. Does not respond to punishment procedures.

24. Delays in copying the lesson written on the board.

25. Many errors in writing and reading.

26. Talks a lot during the lesson.

27. Makes noisy voices during the lesson.

28. Leaves classroom (or exam) before his colleagues.

29. Impatient.

30. Complaining of doing any thing.

31. Unorganized start of work.

32. Low participation in class without permission.

33. Moves from one task to another without completing the first one.

34. Moves around the class without permission.

35. Less attentive to others speech.

36. Has difficulty in memorizing.

37. Hates tasks requiring attention conceatration.

38. Forgets bringing his school tools (pencil, note book ...etc). 


\section{Appendix 2}

\section{Mind Maps' Samples From Arabic Language Class}
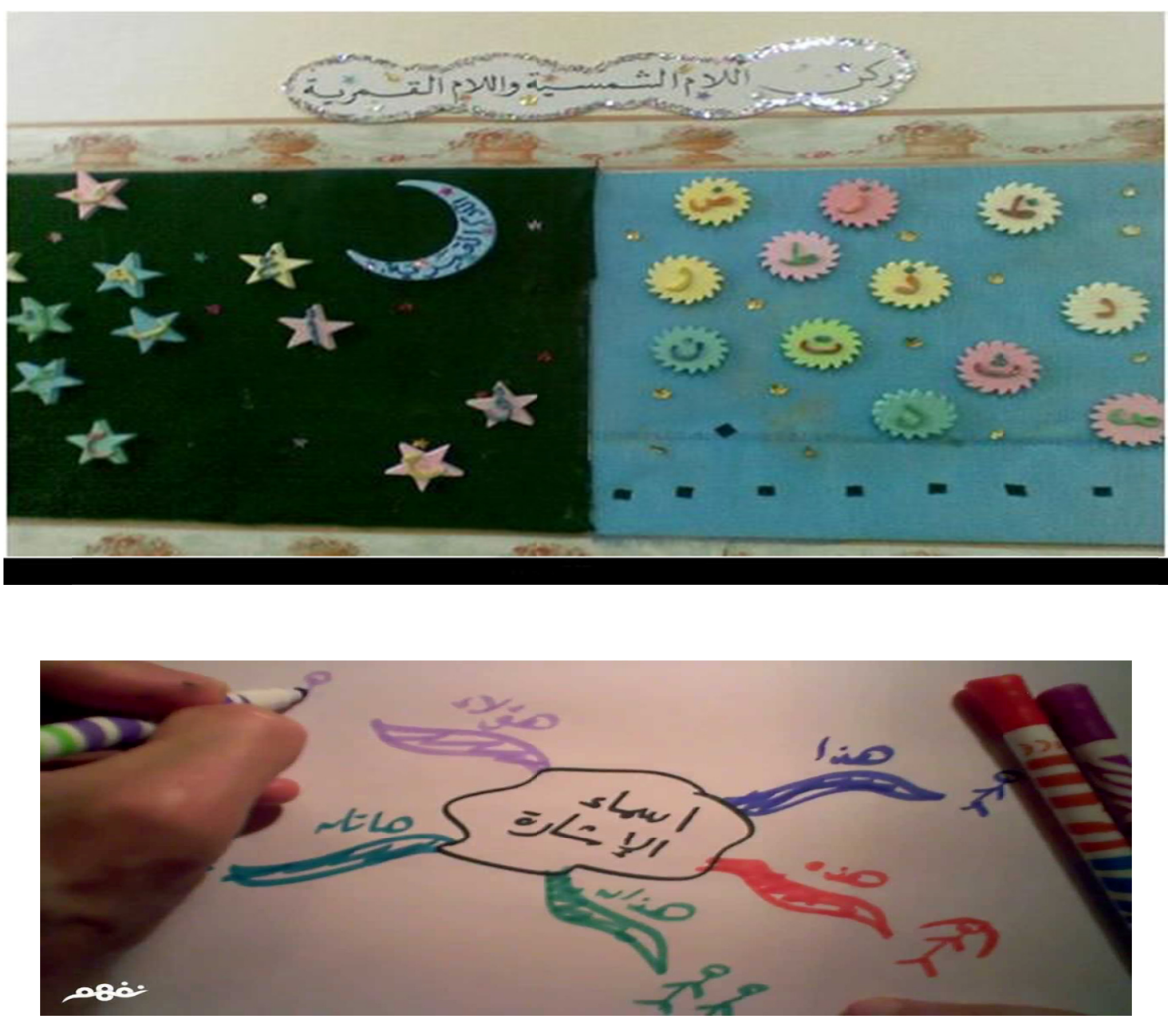

\section{Copyrights}

Copyright for this article is retained by the author(s), with first publication rights granted to the journal.

This is an open-access article distributed under the terms and conditions of the Creative Commons Attribution license (http://creativecommons.org/licenses/by/3.0/). 